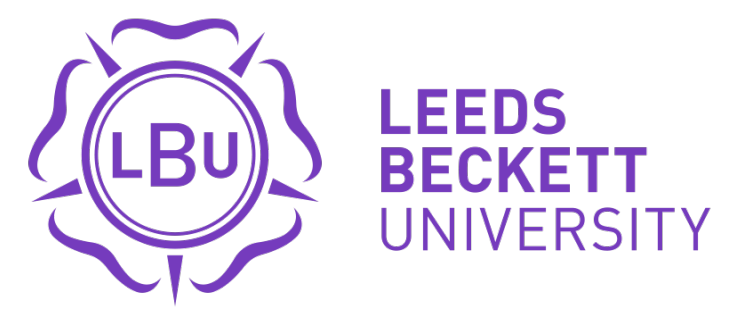

Citation:

Till, KA and Muir, R and Abraham, A and Piggott, D and Tee, J (2019) A Framework for DecisionMaking within Strength \& Conditioning Coaching. Strength and Conditioning Journal, 41 (1). pp. 14-26. ISSN 1533-4295 DOI: https://doi.org/10.1519/SSC.0000000000000408

Link to Leeds Beckett Repository record:

https://eprints.leedsbeckett.ac.uk/id/eprint/5001/

Document Version:

Article (Accepted Version)

The aim of the Leeds Beckett Repository is to provide open access to our research, as required by funder policies and permitted by publishers and copyright law.

The Leeds Beckett repository holds a wide range of publications, each of which has been checked for copyright and the relevant embargo period has been applied by the Research Services team.

We operate on a standard take-down policy. If you are the author or publisher of an output and you would like it removed from the repository, please contact us and we will investigate on a case-by-case basis.

Each thesis in the repository has been cleared where necessary by the author for third party copyright. If you would like a thesis to be removed from the repository or believe there is an issue with copyright, please contact us on openaccess@leedsbeckett.ac.uk and we will investigate on a case-by-case basis. 


\section{A Framework for Decision-Making within Strength \& Conditioning Coaching}

Kevin Till, PhD, Reader in Sports Coaching at Leeds Beckett University

Bob Muir, MSc, Senior Lecturer in Sports Coaching at Leeds Beckett University Andrew Abraham, PhD, Head of Subject Sports Coaching at Leeds Beckett University Dave Piggott, PhD, Principal Lecturer in Sports Coaching at Leeds Beckett University Jason Tee, PhD, Senior Lecturer in Sports Coaching at Leeds Beckett University 
A Framework for Decision-Making within Strength \& Conditioning Coaching

Key Words: Coaching, Learning, Education, Expertise, Effectiveness, Constructive Alignment 


\begin{abstract}
Decision-making is a key factor in developing coach expertise and effectiveness. This article presents a framework for enhancing coach decision-making within strength and conditioning (S\&C). Based on theoretical understanding of the athlete (the 'who'), S\&C training principles and sport demands (the 'what') and learning theories and behaviour (the 'how'), coaches can enhance S\&C practice ('planning, delivering and reflecting'). In addition, understanding contextual challenges ('context, culture \& politics') and own beliefs, values and behaviours ('self') must be considered. Recommendations are presented for implementing constructively aligned learning programmes based on the decision-making framework for enhancing coach learning and professional development within S\&C.
\end{abstract}




\section{Introduction}

In recent years the popularity of strength and conditioning (S\&C) has increased. This has resulted in multiple $S \& C$ educational institutions including degree programmes (e.g., 18 postgraduate degrees in the United Kingdom), coaching qualifications and accreditations with international S\&C associations (e.g., National Strength and Conditioning Association; United Kingdom Strength and Conditioning Association; Australian Strength and Conditioning Association). Further, more opportunities are now available for a career in the industry across a variety of contexts (e.g., professional sport to the fitness industry). However, to maximise the development of the participant or athlete (referred to as athlete from this point forth) it is important that both S\&C coaches and educational institutions work towards developing S\&C coach expertise (36) and enhancing S\&C coach effectiveness (35) within the industry to maximise the development of both their athletes and coaches.

There seems little doubt that decision-making plays an important part in a coaches' everyday practice, and is a significant component of both coach expertise (59) and being effective in achieving their goals (20). Within S\&C, we argue that this is no different (35), with S\&C coaches needing to make decisions daily for the effective implementation of their practices. Such decisions could range from intuitive, short-term, 'delivery' based decisions (e.g., providing feedback to correct an athlete's squat technique) to more classical, deliberate, 'planning' based decisions (e.g., the periodization of a 4-year training programme for an Olympic athlete (7)). Whilst decisions across this continuum will naturally occur within S\&C, it has been suggested that coaches should engage in more thorough and considered decision-making processes as it supports both the coach and athlete to clarify expectations providing a reference point against which progress can be monitored and more thoughtful reflection can occur (7).

Such consideration of this decision-making process poses questions for the $S \& C$ industry. For example, what knowledge do coaches draw upon to inform their decisionmaking behaviours? What knowledge do educational institutions aim to develop within their programmes? Recently, a range of knowledge requirements for the S\&C coach have been proposed, including professional, interpersonal and intrapersonal knowledge (35); and foundational (e.g., planning) and applied (e.g., coaching pedagogical strategies) practical knowledge (26). Furthermore, recommendations have emphasized the importance of applied coaching skills over exercise science knowledge within S\&C $(63,91)$. Therefore, to develop S\&C coaching expertise and effectiveness a combination of theoretical, applied and experiential knowledge is necessary for S\&C coach education and development, potentially challenging current programmes.

To the authors' knowledge, no conceptual framework has been proposed for informing S\&C coach decision-making. However, within sport coaching, Abraham, Muir and colleagues $(2,5,7,73,74)$ have developed a framework for enhancing coach decisionmaking that incorporates six broad interrelated domains of theoretical and applied knowledge. This framework has been embedded within the European Sports Coaching Framework (54), the International Council for Coaching Excellence standards for higher 
education sports coaching degrees (52) and has been adopted by several national governing bodies (e.g., the Football Association). However, to date the adoption and application of these principles have not yet been explored within the field of S\&C.

Therefore, the primary aim of this article is to present a conceptual framework for decision-making within S\&C coaching. It is suggested that this conceptual framework would be of benefit to the entire field of S\&C coaches and educators for considering decisionmaking within S\&C alongside the knowledge required for enhancing S\&C learning and practice. The secondary aim is to propose how constructively aligned learning programmes, related to the decision-making framework, could be applied by S\&C educators to enhance the education, learning and professional development of S\&C coaches.

\section{A Framework for Decision-Making within S\&C Coaching}

The framework for decision-making within S\&C coaching (Figure 1) is based on the premise that $S \& C$ coaches make decisions and shape their strategies for intervention based on six broad domains of theoretical and applied knowledge. These six domains include an S\&C coach's' understanding of:

1. Their athlete (i.e., the 'who').

2. The principles of $S \& C$ coupled with the demands of the sport within which the athlete competes (i.e., the 'what').

3. The principles of skill acquisition and learning (i.e., the 'how').

4. The social, cultural and political context within which they operate (i.e., 'context, culture \& politics')

5. Their existing knowledge, beliefs, values and behaviours (i.e., 'self').

6. The coaching process, referred to as their 'planning, delivering and reflecting' ( $P$ D-R) practices.

\section{$* * *$ Insert Figure 1 near here ${ }^{* * *}$}

These six broad domains of knowledge illustrate the interdisciplinary nature of S\&C coaching. Subsequently, S\&C practice entails the constant integration of knowledge from the scientific disciplines (i.e., 'who', 'what' and 'how') alongside the application of personal knowledge (i.e., 'context, culture \& politics' and 'self') to identify and solve problems and implement evidence based practice (28). This practice is implemented within the S\&C coaching process whereby coaches must plan, deliver and reflect upon their progress towards the achievement of their short-, medium- and long-term goals $(2,73)$. In this regard, the framework for $S \& C$ coach decision-making might be thought of as a conceptual 'toolbox', supporting coaches to organise their existing knowledge by considering what it helps them to know or do, whilst also considering the relationship that exists between these six domains. For example, Figure 1 shows a number of interconnecting arrows between the knowledge domains. This demonstrates that although the domains are presented as standalone knowledge areas, there are connections between these areas. Further, the two- 
way arrows between the 'who', 'what', 'how', 'P-D-R' and 'self' with the outside of the figure demonstrates that knowledge in all these areas is influenced by the understanding of 'context, culture \& politics', ultimately where S\&C coaching is undertaken.

The following sections summarize some of the existing theories, concepts and principles that might be drawn on as 'thinking tools' to inform a S\&C coach's decisionmaking behaviour in relation to each of the six interdependent domains of the framework. The term 'thinking tool' is used to highlight the role of existing theoretical knowledge in supporting coaches' reasoning, reflecting and strategizing for action $(71,78)$. In this sense, 'thinking tools' are not offered as prescriptions for practice, but to stimulate reflection and creativity. However, it is important to note that whilst this paper draws on a selection of theories, concepts and principles, which 'thinking tools' are employed should be determined by the needs of the athlete and sporting context.

\section{Understanding the 'who'}

With the athlete central to the S\&C coach's practice, developing an in-depth understanding of the 'who' is vital for all coaches in undertaking the athlete needs analysis process. Using theories or concepts from a variety of sport science disciplines - including physiology, biomechanics, psychology and sociology - allows coaches to better understand their athletes, explain differences between individuals and create individual goals (74). Thinking tools for the 'who' include: gender (56), age (i.e., chronological, biological, developmental, training age; (58)), sport and positional demands (23), injury and health history (45), athletic (fitness) profiles (68), recovery (83), wellbeing (70), sleep (86), motivations (90), psychological characteristics (61) and social support (e.g., parents, peers, coaches (94)).

The knowledge of the 'who' can be supported by principles related to child and human development, where a range of athlete developmental models have been proposed. For example, the Long-Term Athlete Development model (LTAD; (10)) and Youth Physical Development model (YPD; (57)) are popular within S\&C. Although such models help describe generic needs for youth athletes, practitioners should conduct their own needs analysis through interaction, discussion and data collection to evaluate the motivations, and strengths and weaknesses of individual athletes to develop an appropriate set of physical, psychological and social goals. Within S\&C, previous work (65) has proposed a physical needs analysis process including:

1. Performance Needs Analysis (Demands of the Sport/Activity and Individual)

2. Test Selection

3. Conduct Testing (Interpretation, Analysis and Evaluation of Results)

4. Programme Design and Implementation

Although this process is appropriate for $\mathrm{S} \& \mathrm{C}$, and is regularly referred to when presenting needs analyses within sports (e.g., female soccer $(101,102)$; netball (96); rugby 
league (98)) it may not fully acknowledge the complexities of understanding the holistic aspects of the individual athlete. The range of factors described above may be considered as part of the needs analysis process to allow appropriate group and individual objectives to be developed to aid practices on a short (e.g., daily) and long-term (e.g., macrocycle) basis.

\section{Understanding the 'what'}

Within S\&C the 'what' relates to understanding the scientific principles and exercise techniques for implementation within practice alongside understanding the athlete's sport or activity. The scientific principles are usually the predominant subject matter within S\&C education programmes (63) and key S\&C resources (e.g., (38)). Thinking tools for the 'what' include: physiology (e.g., metabolic demands (32)), biomechanics (e.g., muscular action (64)), principles of training, periodization and adaptation (13), measurement and evaluation $(66,67)$, training modalities (e.g., warm up; $(40))$, exercise technique (17), injury and injury prevention (80) and other areas (e.g., nutrition (89); psychology (90)).

The 'what' knowledge is therefore the scientific knowledge that underpins training programme design for optimising physical adaptation and prescribing safe and effective S\&C practices. Such understanding should link to the athletes needs to achieve the desired outcomes (e.g., if we want to develop strength what is the most effective way to achieve this [biomechanically and physiologically]), be appropriate for the athletes age and stage of development and within the athlete's context. Here it is important to consider that there may be multiple methods to achieve the same outcome (e.g., endurance performance could be enhanced via continuous training, interval training or small sided games). Further, the understanding of technical efficiency and a technical model for exercises (e.g., weight lifting, speed agility, plyometrics) should be developed with a range of examples within S\&C available (e.g., Back Squat (76); Athletic Ability Assessment (69)).

In addition to this scientific and exercise knowledge, the 'what' domain also entails specific knowledge of the sport (or activity) in which the coach works. For example, S\&C coaches working in rugby need to understand the impacts endured in games, the frequency and length of high-intensity efforts, how these vary by position (27) and even by team, according to the head coach's playing style (95). An approach to the P-D-R of physical training that is led by an analysis of the tactical demands of sport is becoming popular in soccer (16). This so-called 'tactical periodization' (93) approach assumes that all coaching staff in a professional setting share an understanding of the demands of the game, with integrated technical, tactical and physical training to help players meet those demands. For example, a soccer team that plays an aggressive, high-pressing style of defense will need players who can maintain high-intensity, intermittent bursts of speed for long periods of the game. It is arguably up to the lead coaching staff (e.g., head coach) to define a clear 'performance model' and share this with S\&C coaches in order to achieve such integration $(82,95)$.

Finally, understanding the 'what' may also apply to the roles of the S\&C coach based on the analysis of the job $(9,103)$. Such analysis suggests that further education of 'what' 
aspects may be necessary for enhanced coach expertise and effectiveness. For example, it has been suggested that knowledge of select psychological techniques (81) are required due to the high contact demand of S\&C coaches with their athletes. Therefore, education and coach development content around coach decision-making may not just be related to the traditional scientific knowledge of S\&C and broadening coach's understanding may equip coaches with more methods to implement within practice (i.e., more tools within their toolbox).

\section{Understanding the 'how'}

Recent arguments have suggested that S\&C coaching is a form of teaching (39) and appropriate pedagogies may enhance S\&C coaches' practice. Drawing on theories and learning from skill acquisition allows $S \& C$ coaches to design and shape the training environment and align appropriate behaviours to support player engagement, generate feedback and make sense of progress towards the athlete's goals (74). Coaches need to make decisions on what practice activities are most suitable to meet the needs of their 'who' and the desired adaptation they require for the 'what'. Therefore, coaches may spend more time planning and thinking about their activity structure and associated coaching behaviours to achieve specific objectives. For example, if strength development is the goal then the activity structure and coaching behaviours will differ between an elite adult and inexperienced youth athlete due to their physical, psychological and social needs. An elite adult performer may require low volume, high-intensity sessions with large rest periods supported by motivational (i.e., encouragement) coach behaviours to elicit strength development. However, such approaches within large groups of young athletes may not be appropriate with more 'time on task' required to stimulate adaptations alongside the learning of technique supported by direct observation, cueing and correction of movement, to enhance athlete competence and autonomy (84).

S\&C coach's behavioural strategies have been evaluated (62) showing silent monitoring, session management and hustle were the most popular coach behaviours within elite S\&C coaches. Holt (39) recently proposed a range of pedagogical methods for S\&C coaches including instructional technique, scaffolding, session organisation and management, communication (e.g., facial expression, gesture, positioning and posture (8)), demonstration and questioning. Tod and colleagues (99) reported that S\&C coaches cited developing trust, being flexible and motivating athletes as the most influential aspects of their coaching, over scientific principles, emphasising the importance of learned practical knowledge for effective coaching. Further, Szedlak et al. (92) interviewed athletes to understand their perceptions of S\&C coach behaviours showing coaches relationships (e.g., trust, approachability, sense of humour) and actions (e.g., feedback, instruction, communication and organisation) may enhance the S\&C coach's effectiveness and may be a model for self-reflection. In addition, recent research has evaluated the effects of cueing (105) and visual feedback (104) on athlete physical performance as ways of assessing the 'how' within S\&C. Although a complex and developing area, it is important for the S\&C 
coach to judge and plan 'how' strategies based on their understanding of the 'who' and 'what' to ensure appropriate pedagogical approaches are implemented. Such concepts have recently been promoted within the S\&C industry (11).

\section{Understanding the 'context, culture \& politics'}

S\&C coaches' practice will always be shaped and influenced by the context within which they work. This can include the organisation's values, accepted practices and traditions, resources, physical constraints (e.g., facilities), and, most of all, other people (e.g., players, other coaches, club officials, support staff, parents). For example, the playing level of the athlete (e.g., adult professional club vs. junior community club) significantly influences the player and development context with differing aims, resources and abilities. Further, the values and current practices of the head coach within a sports organization will influence the context and culture of the daily practices of the S\&C coach. Therefore, practitioners can draw on a range of theories and concepts from social science to understand this layered context (77). This could include the theories of policy, power and politics (42) or philosophical work around the theory and concept of ethics (24). Further, understanding the dynamics of power relationships and the subtle influences that dominant traditions have on the behaviour of athletes and the conduct of coaches may be useful in identifying and overcoming flawed approaches to S\&C training (34). Strategies coaches could utilize to achieve success within their context and against these constraints could include developing a shared vision and purpose, establishing role clarity across the group, aligning behaviours that contribute to the achievement of the goals and nested thinking and planning (see the Understanding the coaching process: Planning, delivering and reflecting section).

\section{Understanding 'self'}

The S\&C coach's understanding of their own beliefs, behaviours and values is crucial in determining quality coaching practice and ongoing personal development (15). Previous work (35) has highlighted the importance of both interpersonal (e.g., social context, relationships) and intrapersonal (e.g., coaching philosophy and values, self-reflective and self-monitoring, lifelong learning, self-regulation) skills and knowledge. Grant and Dorgo (35) suggested individuals thirst for knowledge (e.g., reading, observing, discussing) combined with application through the coaching process (P-D-R) are essential in the development of expertise within S\&C. Interviews with serial winning coaches (consistently high performing coaches) identified four common themes: Philosophy, Vision, Environment and People (53). The philosophy related to the coaches having clear values, beliefs and goals alongside a desire for coaching, a thirst for knowledge and a quest for self-improvement. These elements need to be considered within an S\&C coach's development and therefore should be a focus of education programmes and professional development opportunities. Such activities to support this professional development include undertaking a coach selfevaluation and needs analysis (106), using the Coaching Practice Planning and Reflective 
Framework (CPPRF; see the Understanding the coaching process: Planning, delivering and reflecting section) or by $S \& C$ educators developing and implementing constructively aligned learning programs (see the Developing the S\&C Coach section).

\section{Understanding the coaching process: Planning, delivering and reflecting (P-D-R)}

The preceding sections have outlined a number of theories, concepts and principles that can be used as 'thinking tools' to facilitate S\&C coaching practice. Given the breadth and depth of factors that have been considered, the expertise that $S \& C$ coaches exhibit is the ability to integrate ideas from these interdependent areas to inform their reasoning and decision-making when P-D-R $(1,2,73)$. It is of note, therefore, that decision-making in P-D-R occurs in two broad forms; slow and deliberate or fast and intuitive (46). A third form known as recognition primed decision-making (55) may occur where some time is available for thought, but the required response time is relatively short. A full discussion of these forms of decision-making is beyond the remit of this paper but it is worth noting the alignment of these with the commonly held view of coaching being about planning (i.e., slow and deliberative), delivering (i.e., fast and intuitive) and reflecting (i.e., slow and deliberative).

A key aspect of effective planning is 'beginning with the end in mind' (22); identifying the target performance relative to the athlete's current context in order to formulate outcome, performance and process goals over varying timescales. This entails a conscious and thoughtful consideration of the 'who', 'what' and 'how' to develop a coherent, progressive and 'nested' coaching plan (2). Within the S\&C literature, an extensive body of work refers to the principle of periodization when considering medium to long-term planning strategies (e.g., $(14,37))$. This body of work and the broader principles of periodization provide a useful platform upon which training plans can be developed. Done well, planning provides a 'tentative' map to follow. In this sense, planning might be more usefully thought of as a navigation device that provides a sense of direction and clarifies expectations against which progress can be continually monitored, and alternative strategies, to accommodate and respond to the changing needs of athletes (71).

Indeed, S\&C coaches can only intervene, halt proceedings or change direction within a training session, if they notice the need to act in the first place. Noticing relies on coaches consciously attending to moments of importance or disruption. What is worth noticing then becomes an important matter for $\mathrm{S} \& \mathrm{C}$ coaches to consider. Engaging in deliberate and purposeful planning enables coaches to clarify their expectations and begin to notice things that might otherwise go unnoticed $(41,71)$. Writing a training programme therefore constitutes only a small part of the planning process. The planning strategy advocated here is one that is ongoing, dynamic and adaptive, enabling coaches to respond to the changing needs of their athletes and the sporting context $(2,47,48)$.

A thinking tool that $S \& C$ coaches can use to clarify expectations and promote connections between the desired objectives and the associated coaching strategies is the Coaching Practice Planning and Reflective Framework (CPPRF: $(71,73,74)$ ). The CPPRF has been used to support the P-D-R practices of a number of National and Olympic coaches in a 
range of sports (e.g., boxing, sailing (71)). The CPPRF was developed to encourage coaches to consider the relationship between their P-D-R practices. More specifically, it encourages coaches to explore the relationship between their: 1) coaching objectives (goals), 2) training activities, 3) behavioural strategies, and 4) athlete engagement and learning. As such, the CPPRF is structured around these four interdependent areas (Figure 2).

\section{*** Insert Figure 2 near here ${ }^{* * *}$}

As described above, $S \& C$ coaches are essentially equipped with two pedagogical strategies to support athlete learning and development:

1. The way they structure the learning experience for their athletes through their training activities (e.g., circuits, weight programmes, drills, games). Such strategies could range from game centred to technique centred approaches based upon the session objectives.

2. The behavioural strategies they employ to support athletes before, during and after each training activity. This could range from a problem solving to problem setting approach using a range of behaviours (e.g., timing and type of feedback; open or closed questioning; demonstrations; hustles; instructional prompts)

Thus, employing the CPPRF as a 'thinking tool' encourages S\&C coaches to deliberately plan, manipulate and align their training activity structure and their behavioural strategies to maximise athlete engagement and development opportunities (72).

As a planning tool the CPPRF encourages coaches to spend time considering their coaching goals and how these align with the needs of their athletes (i.e., the 'who'), the demands of the sport (i.e., the 'what') and the learning environment they orchestrate (i.e., the 'how') to clarify expectations in training. This planning process should entail the constant integration and alignment of these interdependent areas. Spending time considering these factors enables coaches to explicitly plan for and implement S\&C coaching that is developmentally appropriate, builds on where the athlete has come from and helps prepare them for where they wish to go (73). Furthermore, a clear understanding of how each coaching interaction is nested within the long-, medium- and short-term objectives of an overall developmental performance system enables $\mathrm{S} \& \mathrm{C}$ coaches to make more informed adjustments from predetermined plans based on observations, evaluations and reactions to 'goings on' within the training and performance environment $(2,44,47)$. Our capacity to 'think on our feet' in this manner is often referred to as a process of reflectionin-action $(51,87)$. Reflection-in-action assumes that problems do not always present themselves but arise because of a mismatch between the session goals/expectations and the reality that has emerged from putting the plan into practice. By increasing the clarity of our expectations before a coaching event we increase our opportunity to reflect-in-action, which in turn also provides a powerful stimulus for reflection-on-action (i.e., after the coaching event). 
Reflective practice is generally characterised as a conversation between planning and delivery through which we can develop a better appreciation of our experience and become more skilful in our practice (88). Reflective practice therefore provides a vehicle to question and re-examine the reasoning and strategies that underpin our practice; to consider the 'what', 'how' and 'why', providing the opportunity to evaluate what benefits our current practice brings and what might be better for ourselves and the athletes we work with. This could involve reflection and evaluation of training sessions or training programmes from a meso and macro level. Programme reflection and evaluation may entail S\&C coaches assessing the physical changes that have occurred due to their programme to evaluate the improvement of their athletes. For example, S\&C coaches may evaluate the medium (i.e., 6 weeks) and seasonal changes in sprint speed and strength within their athletes. Such evaluations will likely display large variability in response (97) but S\&C coaches need to not only consider the data but reflect upon the implementation of the programme related to the 'who' (e.g., athlete's motivation), 'what' (e.g., exercise selection) and 'how' (e.g., feedback provided) of their programme design.

A final consideration for $S \& C$ coaches in shaping their P-D-R strategies is the insights, ideas and understanding of the other practitioners that they invariably work alongside (e.g., head coach, physiotherapists, sport scientists). Each disciplinary perspective offers a great deal and should be harnessed to formulate a shared understanding within a multidisciplinary team about 'what' to prioritise and work on, and 'how' to support the athletes' in order to meet their needs. This is exemplified within the idea of 'tactical periodization' $(16,93)$ and the development of a 'performance model' $(82)$ when working with the head coach and other sports coaches. In this regard, communication, openness and collaboration within a culture of working towards the same goal are essential for an effective high performing team in sport (33).

\section{Developing the S\&C Coach: Constructive Aligned Learning Programs and Professional Development}

Thus far in this paper the role of the six broad domains of the decision-making framework for guiding the practice of the S\&C Coach have been discussed. This framework demonstrates the $S \& C$ coach as an interdisciplinary practitioner working in complex environments who has to think in complex ways to practice effectively. Clearly, this level of practice does not simply appear one day, it is the result of significant periods of learning. That is not to say that any S\&C coach, regardless of level (i.e., novice to expert) cannot benefit from considering S\&C practice as a decision-making activity using 'thinking tools' from the six domains discussed. Therefore, a question that arises is how does this learning take place and what role can educational institutions (i.e., higher education and national associations) play in this learning?

Within the coach development literature three broad approaches to supporting learning are identified; formal (e.g., institutionalized accredited learning), non-formal (e.g., conferences) and informal (e.g., tacit, experiential, self-directed learning). Furthermore, 
there will be some level of blurred boundaries between these learning approaches (e.g., gaining accreditation points for attending a conference; formal/non-formal), Therefore, it is important to consider how institutions can facilitate formal learning to support non-formal and informal learning opportunities for enhancing S\&C coach development. As the coach learning, and more broadly, adult learning literature is large and varied it is not possible to capture all this literature here. Instead, a pragmatic path that is utilized extensively within higher education is proposed; constructive alignment of learning. Constructive alignment was originated by Biggs (12) and has been adapted for providing a basis for thinking about coach learning (60).

Constructive alignment is displayed in Figure 3 and discussed in the following sections. Constructive alignment refers to how all aspects of an educational program design should align from one consideration to the next. Furthermore, any decisions on program design should be informed by external standards such as policy, research and the coach's needs.

\section{***Insert Figure 3 near here***}

\section{Program learning outcomes and guidance capabilities}

Table 1 summarizes numerous ways in which program learning outcomes and/or guidance capabilities can be informed through published work within coaching and S\&C (4, $6,31,100)$. This work identifies some key themes that appear to be important in S\&C coaching, including; problem solving, program planning and delivery, relationships, safe practice, sound knowledge base, session delivery, reflection, self-improvement and maintaining currency. Therefore, such information should be used to develop learning outcomes and guidance capabilities for S\&C education. The language used in the creation of these outcomes is important, as it is typically focused on those who are 'high-achieving' or beyond graduate level. For example, the UKCCE and Professional practice statements reflect a 'professional' level of practice that is achieved after previous formal development. As such, some reverse engineering would be required to consider creating steps (e.g., levels of development) to high achievement (e.g., guidance capabilities) between novice (e.g., undergraduate students) and expert coaches. For a discussion of levelness in creating learning outcomes see $(19,30)$.

\section{Assessment}

The assessment stage is probably the most counterintuitive of the constructive alignment process. Many educators will want to think about assessment after they have considered what is being taught. However, within constructive aligned programs, assessment becomes more about 'assessment for learning' rather than 'assessment of learning' (3). Assessment is the means of evidencing the achievement of the desired outcomes to both learner and tutor. It also means that feedback should be facilitative of future development. For example, if Build and maintain effective coach-participant 
relationships is a learning outcome then this should drive the assessment alongside the criticality of the thinking. Relationships don't occur in a single session, nor are they things that can just be 'seen' by an assessor. They are the result of judgements and interactions informed by an ongoing knowledge and awareness of knowing the 'who', 'how' and 'self'. It is therefore recommended that assessments attempt to draw upon these factors within the assessment process.

\section{Necessary learning activities}

This is a hugely complex area as learning activities should be considered based on an interaction between the needs of the learner, the knowledge and/or skills being developed, learning theory and available resources. In keeping with the pragmatic approach of this paper, some key principles that can guide thinking in this area can be achieved by simplifying coaching to the P-D-R process. This process relies onf coaches having professional knowledge and skills to engage in each part of this process. Planning and reflecting are the analytical and thoughtful parts of the process. These rely on the capacity to know and assimilate knowledge from the six domains and the 'thinking tools' presented in this paper. Within learning activities, these 'thinking tools' are recommended to be introduced in classroom sessions (21).

Progressing beyond this approach, creating opportunities to engage in the actual problem of P-D-R, by drawing on realistic and meaningful contexts (ideally the coach's own), is crucial (43). This could include practicums, internship and mentorships $(25,85)$ allowing coaches the opportunity to apply ideas, experiment and learn through applied practice grounded in the coach decision-making framework. For example, inexperienced coaches may benefit from practicum activities within educational settings (i.e., delivering sessions to peers, observation) leading to applied internships within sport for postgraduate students to mentorship opportunities for experienced coaches (75). Regardless of the level, opportunities to discuss, reflect and challenge S\&C practice should be integrated with in education programmes to enhance learning rather than just providing practice-based opportunities alone.

Delivery is the more naturalistic element of coaching due to being in the moment, and reading and reacting to situations (e.g., perceptual skills). This is a concept known as sense making $(49,50)$. Phillips and colleagues $(79)$ identified the need for engaging in;

- deliberate practice, this is one reason why planning is so important as it raises expectations of what goals are and what the perceptual cues will be.

- obtaining feedback that is accurate and timely

- reflect on expectations and perceived reality to seek out and explore uncertainty in practice

In reality, people are constantly attempting to make sense of their reality, whether that is in P-D-R. This is often the most confusing part of learning for learners. Consequently, 
numerous researchers (e.g. $(18,29))$ have discussed the role of mentors in supporting learners in engaging in this sense making process.

\section{Packaging units of learning}

For many in formal education this is often the starting place of creating learning programmes in the form of units, modules or classes. However, it is hopefully clear why this in fact should be final part of the puzzle (not withstanding that the whole process is both feed-forward and feed-back). This is the part where curriculum, delivery and assessment come together to ensure alignment. For example, whether an expected professional skill has been sufficiently supported by aligned professional knowledge and/or the opportunity to develop this in the field (or assessment) is required.

\section{Conclusion}

This article presents a conceptual framework for decision-making within S\&C coaching. Based on theoretical understanding of the athlete (the 'who'), the sport and S\&C training principles (the 'what') and learning theories and their behaviour (the 'how'), coaches can enhance S\&C practice ('planning, delivery, reflecting'). In addition, S\&C coaches can consider their integration with other practitioners while considering the contextual challenges (the 'context, culture \& politics') and their own beliefs, values and behaviours ('self') for enhancing coach expertise and effectiveness. Based on this framework, coach educational institutions should aim to utilise this coach decision-making framework for improving S\&C education and professional development within the field. The implementation of constructively aligned formal learning programmes would allow implementation of learning outcomes, assessment and learning activities related to the responsibility of the $S \& C$ coach. Such programmes would then have knock on effects to how organizations may then engage in the creation of continued professional development (i.e. non-formal) or how coaches decide on which informal learning opportunities they seek. Essentially, a well-developed formal structure based on the decision-making framework should allow for the enhancement of $S \& C$ coach learning.

\section{Conflicts of Interest}

There are no conflicts of interest 


\section{References}

1. Abraham A, and Collins D. Effective Skill Development: How Should Athletes' Skills Be Developed?, in: Performance Psychology: A Guide for the Practitioner D Collins, H Richards, A Button, eds. London: Churchill Livingstone, 2011, pp 207-230.

2. Abraham A and Collins D. Taking the Next Step: Ways Forward for Coaching Science. Quest 63: 366-384, 2011.

3. Abraham A, Collins D, Morgan G, and Muir B. Developing expert coaches requires expert coach development: Replacing serendipity with orchestration. Aportaciones teoricas y practicas para el baloncesto del futuro: 23-37, 2009.

4. Abraham A, Morgan G, North J, Muir B, Duffy P, Allison W, and Hodgson R. Task analysis of coach developers: Applications to the FA youth coach educator role. Presented at Proceedings of the 11th International Conference on Naturalistic Decision Making (NDM 2013), 2013.

5. Abraham A, Muir B, and Morgan G. National and international best practice in level 4 coach development. Leeds Metropolitan University \& The UK Centre for Coaching Excellence, 2010.

6. Abraham A, Muir B, and Morgan G. UK centre for coaching excellence scoping project report: National and international best practice in level 4 coach development. 2010.

7. Abraham A, Saiz S, Mckeown S, Morgan G, Muir B, North J, and Till K. Planning your coaching: A focus on youth participant development, in: Practical Sports Coaching. C Nash, ed. Abingdon: Routledge, 2014, pp 16-53.

8. Arthur-Kelly M, Gordon C, and Butterfield N. Classroom management: Creating positive learning environments. Thomson, 2003.

9. Baechle TR. National Study Produces a New CSCS Job Description. Strength Cond J 19: 64-65, 1997.

10. Balyi I and Hamilton A. Long-term athlete development: trainability in childhood and adolescence. Olympic Coach 16: 4-9, 2004.

11. Bartholomew B. Conscious Coaching: The Art and Science of Building Buy-In. CreateSpace Independent Publishing Platform 2017.

12. Biggs J. Enhancing teaching through constructive alignment. Higher education 32: 347-364, 1996.

13. Bompa T and Buzzichelli C. Periodization Training for Sports, 3E. Human kinetics, 2015.

14. Bompa TO and Haff GG. Periodization: Theory and methodology of training. Human Kinetics Publishers, 2009.

15. Buchheit, M. Outside the Box. Int J Sports Physiol Perfom 12:1001-1002, 2017.

16. Buchheit $M$, Lacome $M$, Cholley $Y$, and Simpson BM. Neuromuscular Responses to Conditioned Soccer Sessions Assessed Via GPS-Embedded Accelerometers: Insights Into Tactical Periodization. International journal of sports physiology and performance: 1-21, 2017.

17. Caulfield $S$ and Berninger D. Exercise technique for free weight and machine training, in: Essentials of Strength Training and Conditioning. GG Haff, TN Triplett, eds. Illinois, United States: Human Kinetics, 2016, pp 351-408.

18. Collins A, Brown JS, and Holum A. Cognitive apprenticeship: Making thinking visible. American Educator 15: 6-11, 1991.

19. Collins D, Burke V, Martindale A, and Cruickshank A. The illusion of competency versus the desirability of expertise: Seeking a common standard for support professions in sport. Sports Med 45: 1-7, 2015.

20. Côté $\mathrm{J}$ and Gilbert W. An Integrative Definition of Coaching Effectiveness and Expertise. Int Jf Sports Sci Coach 4: 307-323, 2009.

21. Council NR. Learning, remembering, believing: Enhancing human performance. National Academies Press, 1994. 
22. Covey S. The 7 Habits of Highly Effective People: Powerful Lessons in Personal Change. Rosetta Books LLC, 2004.

23. Cummins $\mathrm{C}$, Orr R, $\mathrm{O}^{\prime}$ Connor $\mathrm{H}$, and West $\mathrm{C}$. Global positioning systems (GPS) and microtechnology sensors in team sports: a systematic review. Sports Med 43: 1025-1042, 2013.

24. Denison J and Avner Z. Positive coaching: Ethical practices for athlete development. Quest 63: 209-227, 2011.

25. Dieffenbach KD, Murray M, and Zakrajsek R. The Coach Education Internship Experience: An Exploratory Study. Int J Coach Sci 5, 2011.

26. Dorgo $\mathrm{S}$, Newton $\mathrm{H}$, and Schempp P. Unfolding the Practical Knowledge of an Expert Strength and Conditioning Coach. Int I Sports Sci Coach 4: 17-30, 2009.

27. Duthie G, Pyne D, and Hooper S. Applied physiology and game analysis of rugby union. Sports Med 33: 973-991, 2003.

28. Eisenmann J. Translational Gap between Laboratory and Playing Field: New Era to Solve Old Problems in Sports Science. Translational J American College Sports Med 2: 37-43, 2017.

29. Entwistle NJ and Peterson ER. Conceptions of learning and knowledge in higher education: Relationships with study behaviour and influences of learning environments. Int J Educational Res 41: 407-428, 2004.

30. Epstein RM and Hundert EM. Defining and assessing professional competence. Jama 287: 226-235, 2002.

31. International Sport Coaching Framework. (International Council for Coaching Excellence, Asscoiation of Summer Olympic International Federations, \& Leeds Beckett University, Eds.) (1.2). Champaign, IL: Human Kinetic, 2012

32. French D. Adaptations to anaerobic training programs, in: Essentials of Strength Training and Conditioning. GG Haff, TN Triplett, eds. Illinois, United States: Human Kinetics, 2016, pp 87114.

33. Gabbett, TJ, Kearney, S, Bisson, L, Collins, J, Sikka, R, Winder, N, Sedgwick, C, Hollis, E, and Bettle, JM. Seven tips for developing and maintaining a high performance sports medicine team. Br J Sports Med, 10.1136/bjsports-2017-098426, 2017.

34. Gearity BT and Mills JP. Discipline and punish in the weight room. Sports Coaching Review 1: 124-134, 2012.

35. Gilbert WD and Baldis MW. Becoming an Effective Strength and Conditioning Coach. Strength Cond J 36: 28-34, 2014.

36. Grant MA and Dorgo S. Developing Expertise in Strength and Conditioning Coaching. Strength Cond J 36: 9-15, 2014.

37. Haff GG. 17 The essentials of periodisation. Strength and Conditioning for Sports Performance: 404, 2016.

38. Haff GG and Triplett NT. Essentials of Strength Training and Conditioning 4th Edition. Human kinetics, 2015.

39. Holt A. Using Shulman's pedagogical reasoning model to improve strength and conditioning coaching. J Australian Strength Cond 24: 6-22, 2016.

40. Jeffreys I. Warm-Up and flexibility training, in: Essentials of Strength Training and Conditioning. GG Haff, TN Triplett, eds. Illinois, United States: Human Kinetics, 2016, pp 317350.

41. Jones RL, Bailey J, and Thompson I. Ambiguity, noticing, and orchestration: Further thoughts on managing the complex coaching context, in: The Routledge handbook of sports coaching P.Potrac, W.Gilbert, J.Denison, eds. London: Routledge, 2013, pp 271-283.

42. Jones RL, Potrac P, Cushion C, and Ronglan LT. The Sociology of Sports Soaching. Routledge, 2010.

43. Jones RL and Turner P. Teaching coaches to coach holistically: Can problem-based learning (PBL) help? Physical Education and Sport Pedagogy 11: 181-202, 2006. 
44. Jones, RL, and Wallace, $\mathrm{M}$. The coach as 'orchestrator': more realistically managing the complex coaching context. In: Jones, RL. ed. The Sports Coach as Educator: Reconceptualising Sports Coaching, London: Routledge, 51-64, 2006.

45. Joyce $\mathrm{D}$ and Lewindon $\mathrm{D}$. Sports injury prevention and rehabilitation: integrating medicine and science for performance solutions. Routledge, 2015.

46. Kahneman D and Klein G. Conditions for intuitive expertise: a failure to disagree. American Psychologist 64: 515, 2009.

47. Kiely J. Planning for physical performance: the individual perspective: Planning, periodization, prediction, and why the future ain't what it used to be!, in: Performance Psychology: A Guide for the Practitioner. D. Collins, H Richards, A Button, eds. London: Churchill Livingstone, 2011, pp 139-160.

48. Kiely J. Periodization paradigms in the 21st century: evidence-led or tradition-driven? Int J Sports Physiol Perform 7: 242-250, 2012.

49. Klein G, Moon B, and Hoffman RR. Making sense of sensemaking 1: Alternative perspectives. IEEE intelligent systems 21: 70-73, 2006.

50. Klein G, Moon B, and Hoffman RR. Making sense of sensemaking 2: A macrocognitive model. IEEE Intelligent systems 21: 88-92, 2006.

51. Kuklick CR and Gearity BT. A Review of Reflective Practice and Its Application for the Football Strength and Conditioning Coach. Strength Cond J 37: 43-51, 2015.

52. Lara-Bercial S, Abraham A, Colmaire $P$, Dieffenbach $K$, Mokglate $O$, Rynne $S$, Jiménez A, Bales J, Curado J, and Ito M. The International Sport Coaching Bachelor Degree Standards of the International Council for Coaching Excellence. Int Sport Coach J 3: 344-348, 2016.

53. Lara-Bercial S and Mallett CJ. The practices and developmental pathways of professional and Olympic serial winning coaches. Int/ Sport Coach J 3: 221-239, 2016.

54. Lara-Berical S, North J, Hamalainen K, Oltmanns K, Minkhorst J, and Petrovic L. European Sports Coaching Framework. Illinois, United States, 2017.

55. Lipshitz R, Klein G, Orasanu J, and Salas E. Taking stock of naturalistic decision making. Journal of Behavioral Decision Making 14: 331-352, 2001.

56. Lloyd RS and Faigenbaum AD. Age- and sex-related differences and their implications for resistance exercise, in: Essentials of Strength Training and Conditioning. GG Haff, TN Triplett, eds. Illinois, United States: Human Kinetics, pp 135-154, 2016.

57. Lloyd RS and Oliver JL. The youth physical development model: A new approach to long-term athletic development. Strength Cond J 34: 61-72, 2012.

58. Lloyd RS, Oliver JL, Faigenbaum AD, Myer GD, and Croix MBDS. Chronological age vs. biological maturation: implications for exercise programming in youth. J Strength Cond Res 28: 1454-1464, 2014.

59. Lyle J. Planning for team sports, in: Sport Coaching: Professionalisation and Practice. JLaC Cushion, ed. London: Churchill Livingstone, 2010, pp 85-98.

60. Lyle J, Abraham A, Morgan G, and Muir B. UKCC Level 4 Guidance Document. Leeds: Sportscoach UK, 2010.

61. MacNamara Á, Button A, and Collins D. The role of psychological characteristics in facilitating the pathway to elite performance part 1: Identifying mental skills and behaviors. The Sport Psychologist 24: 52-73, 2010.

62. Massey CD, Maneval MW, Phillips J, Vincent J, White G, and Zoeller B. An analysis of teaching and coaching behaviors of elite strength and conditioning coaches. J Strength Cond Res 16: 456-460, 2002.

63. Massey D. Program for effective teaching: A model to guide educational programs in strength and conditioning. Strength Cond J 32: 79-85, 2010.

64. McBride JM. Biomechanics of resistance exercise, in: Essentials of Strength Training and Conditioning GG Haff, TN Triplett, eds. Illinois, United States: Human Kinetics, 2016, pp 1942. 
65. McGuigan M. Evaluating Athletic Capacities. High-Performance Training for Sports D Joyce and D Lewindon, eds Champaign, IL: Human Kinetics: 3-13, 2014.

66. McGuigan M. Administration, scoring and interpretation of selected tests, in: Essentials of Strength Training and Conditioning. GG Haff, TN Triplett, eds. Illinois, United States: Human Kinetics, 2016, pp 259-316.

67. McGuigan M. Principles of test selection and administration, in: Essentials of Strength Training and Conditioning. GG Haff, TN Triplett, eds. Illinois, United States: Human Kinetics, 2016, pp 249-258.

68. McGuigan MR, Cormack SJ, and Gill ND. Strength and power profiling of athletes: Selecting tests and how to use the information for program design. Strength Cond J 35: 7-14, 2013.

69. McKeown I, Taylor-McKeown K, Woods C, and Ball N. Athletic ability assessment: a movement assessment protocol for athletes. Int J Sports Physical Therapy 9: 862, 2014.

70. McLean BD, Coutts AJ, Kelly V, McGuigan MR, and Cormack SJ. Neuromuscular, endocrine, and perceptual fatigue responses during different length between-match microcycles in professional rugby league players. Int I Sports Physiol Perform 5: 367-383, 2010.

71. Muir B. An embedded, relational, emergent coach learning and development intervention strategy for coaching in the performance domain, in: School of Sport. Leeds: Leeds Beckett University, 2018.

72. Muir B, Morgan G, and Abraham A. Player learning: Implications for Structuring Practice Activities and Coach Behaviour. London: Football Association, 2011.

73. Muir B, Morgan G, Abraham A, and Morley D. Developmentally appropriate approaches to coaching children. Coaching children in sport: 17-37, 2011.

74. Muir B, Till K, Morgan G, and Abraham AACFfPyPACsPCIT, K. \& Jones, B. (Eds.) The Science of Sport: Rugby. Crowood Press. . A conceptual framework for planning your practice: A coach's perspective, in: The Science of Sport: Rugby. K Till, B Jones, eds. Marlborough: Crowood Press, 2015, pp 161-175.

75. Murray MA, Zakrajsek RA, and Gearity BT. Developing effective internships in strength and conditioning: A community of practice approach. Strength Cond J 36: 35-40, 2014.

76. Myer GD, Kushner AM, Brent JL, Schoenfeld BJ, Hugentobler J, Lloyd RS, Vermeil A, Chu DA, Harbin J, and McGill SM. The back squat: A proposed assessment of functional deficits and technical factors that limit performance. Strength Cond J 36: 4, 2014.

77. North J. Philosophical underpinnings of coaching practice research. Quest 65: 278-299, 2013.

78. North J. Sport Coaching Research and Practice: Ontology, Interdisciplinarity and Critical Realism. London: Routledge, 2017.

79. Phillips JK, Klein G, and Sieck WR. Expertise in judgment and decision making: A case for training intuitive decision skills. Blackwell handbook of judgment and decision making 297: 315, 2004.

80. Potach DH and Grindtsaff TL. Rehabilitation and reconditioning, in: Essentials of Strength Training and Conditioning. GG Haff, TN Triplett, eds. Illinois, United States: Human Kinetics, 2016, pp 605-622.

81. Radcliffe JN, Comfort P, and Fawcett T. The perception of psychology and the frequency of psychological strategies used by strength and conditioning practitioners. J Strength Cond Res 27: 1136-1146, 2013.

82. Richards $P$, Collins D, and Mascarenhas DR. Developing rapid high-pressure team decisionmaking skills. The integration of slow deliberate reflective learning within the competitive performance environment: A case study of elite netball. Reflective Practice 13: 407-424, 2012.

83. Roe G, Till K, Darrall-Jones J, Phibbs P, Weakley J, Read D, and Jones B. Changes in markers of fatigue following a competitive match in elite academy rugby union players. South African $J$ Sports Med 28: 1-4, 2016. 
84. Ryan RM and Deci EL. Self-determination theory and the facilitation of intrinsic motivation, social development, and well-being. American Psychologist 55: 68, 2000.

85. Rydings D. Pursuing a career in strength and conditioning: Interning. Sport Exerc Sci 26: 2324, 2010.

86. Sawczuk T, Jones B, Scantlebury S, and Till K. Relationships between training load, sleep duration, and daily wellbeing and recovery measures in youth athletes. Ped Exerc Sci 2017.

87. Schön DA. The reflective practitioner: How professionals think in action. New York: Basic Books, 1983.

88. Schön DA. Educating the reflective practitioner: Toward a new design for teaching and learning in the professions. Jossey-Bass, 1987.

89. Spano M. Basic nutrition factors for health, in: Essentials of Strength Training and Conditioning. GG Haff, TN Triplett, eds. Illinois, United States: Human Kinetics, 2016, pp 175200.

90. Statler TA and DuBois AM. Psychology of athletic preparation and performance, in: Essentials of Strength Training and Conditioning. GG Haff, TN Triplett, eds. Illinois, United States: Human Kinetics, 2016, pp 155-174.

91. Stone MH, Sands WA, and Stone ME. The Downfall of Sports Science in the United States. Strength Cond J 26: 72-75, 2004.

92. Szedlak C, Smith MJ, Day MC, and Greenlees IA. Effective behaviours of strength and conditioning coaches as perceived by athletes. Int J Sports Sci Coach 10: 967-984, 2015.

93. Tamarit X. What Is Tactical Periodization? : Bennion Kearny Limited, 2015.

94. Teatro C, Thompson M, Kulinna PH, van der Mars H, and Kwan J. Coaching behaviors and stakeholders' views of coaches' efficacy. Int J Sports Sci Coach 12: 452-460, 2017.

95. Tee JC, Ashford, M. and Piggott, D. A tactical periodization approach for rugby union. . Strength Cond J 2018.

96. Thomas C, Comfort P, Jones PA, and Dos'Santos T. Strength and Conditioning for Netball: A Needs Analysis and Training Recommendations. Strength Cond J 39: 10-21, 2017.

97. Till K, Jones B, Darrall-Jones J, Emmonds S, and Cooke C. Longitudinal development of anthropometric and physical characteristics within academy rugby league players. J Strength Cond Res 29: 1713-1722, 2015.

98. Till K, Scantlebury S, and Jones B. Anthropometric and Physical Qualities of Elite Male Youth Rugby League Players. Sports Med 47: 2171-2186, 2017.

99. Tod DA, Bond KA, and Lavallee D. Professional development themes in strength and conditioning coaches. J Strength Cond Res 26: 851-860, 2012.

100. Triplett NT, Williams C, McHenry P, Doscher M, Plisk S, Brass M, ... , and Wathen D. National Strength and Conditioning Association: Strength and Conditioning Professional Standards and Guidelines. Strength Cond J 31: 14-38, 2009.

101. Turner E, Munro AG, and Comfort P. Female Soccer: Part 1-A Needs Analysis. Strength Cond J 35: 51-57, 2013.

102. Turner E, Munro AG, and Comfort P. Female Soccer: Part 2--Training Considerations and Recommendations. Strength Cond J 35: 58-65, 2013.

103. Waller M, Piper T, and Miller J. National Strength and Conditioning Association: Strength and conditioning professional standards and guidelines. Strength Cond J 31: 14-38, 2009.

104. Weakley JJ, Wilson KM, Till K, Read DB, Darrall-Jones J, Roe G, Phibbs PJ, and Jones B. Visual feedback attenuates mean concentric barbell velocity loss, and improves motivation, competitiveness, and perceived workload in male adolescent athletes. J Strength Cond Res 2017.

105. Winkelman NC. Attentional Focus and Cueing for Speed Development. Strength Cond J 2016. 106. Young W. A self evaluation tool for professional development for strength and conditioning coaches J Australian Strength Cond 25: 29-30, 2017. 


\section{Figure Legends}

Figure 1. A Framework for Decision-Making within S\&C Coaching (adapted from $(2,73,74)$ ) Figure Caption: The interconnecting arrows between the knowledge domains demonstrate that although the domains are presented as standalone knowledge areas, there are connections between each of them. The two-way arrows between the 'who', 'what', 'how', 'P-D-R' and 'self' with the outside of the figure demonstrate that knowledge in all these areas is affected and influenced by the 'context, culture \& politics', within which S\&C coaches work.

Figure 2. The Coaching Practice Planning and Reflective Framework (71)

Figure 3: A Schematic of Constructive Alignment $(12,60)$. 